\title{
CELLULAR SYSTEM INFORMATION CAPACITY CHANGE AT HIGHER FREQUENCIES DUE TO PROPAGATION LOSS AND SYSTEM PARAMETERS
}

\author{
K. A. Anang* , P. B. Rapajic, R. Wu, L. Bello, and T. I. Eneh \\ Wireless and Mobile Communication Research Centre, School of \\ Engineering, University of Greenwich, UK
}

\begin{abstract}
In this paper, mathematical analysis supported by computer simulation is used to study cellular system information capacity change due to propagation loss and system parameters (such as path loss exponent, shadowing and antenna height) at microwave carrier frequencies greater than $2 \mathrm{GHz}$ and smaller cell size radius. An improved co-channel interference model, which includes the second tier co-channel interfering cells is used for the analysis. The system performance is measured in terms of the uplink information capacity of a time-division multiple access (TDMA) based cellular wireless system. The analysis and simulation results show that the second tier cochannel interfering cells become active at higher microwave carrier frequencies and smaller cell size radius. The results show that for both distance-dependent: path loss, shadowing and effective road height the uplink information capacity of the cellular wireless system decreases as carrier frequency $f_{c}$ increases and cell size radius $R$ decreases. For example at a carrier frequency $f_{c}=15.75 \mathrm{GHz}$, basic path loss exponent $\alpha=2$ and cell size radius $R=100,500$ and $1000 \mathrm{~m}$ the decrease in information capacity was $20,5.29$ and $2.68 \%$.
\end{abstract}

\section{INTRODUCTION}

The common approach for utilizing the radio spectrum efficiently is by reducing the cell size radius of a cellular wireless network. Wireless communication system have evolved from accommodating a large number of voice and/or low speed data service. Now emerging and future wireless system are required to accommodate high-speed data

\footnotetext{
Received 9 August 2012, Accepted 13 September 2012, Scheduled 24 September 2012
}

* Corresponding author: Kwashie Amartei Anang (k.anang@greenwich.ac.uk). 
service. Therefore it is important for wireless systems to achieve a high degree of spectral efficiency. Because the radio spectrum is limited and regulated by international agreements $[1,2]$. Takada et al. in [3] reported that in order to achieve high data rates in wireless system, broadband channels are required. Thus, carrier frequency needs to be increased. References [4-6], also stated that for future mobile wireless systems to meet the demand for high-speed data service they need to be accommodated in frequency bands located above $2 \mathrm{GHz}$. However, at higher carrier frequency cell size needs to be decreased because of an increase in path loss [3].

For larger cell size radius (conventional mobile radio systems) cellular systems, signal variability is characterized by Rayleigh Statistics. Whilst for smaller cell size radius (higher frequency mobile radio systems) cellular wireless system base station (BS) antenna height are placed below the rooftops of surrounding buildings. Thus, establishing a line-of-sight (LOS) radio link between the transmitter and the receiver. This reduces the signal variability as compared to the conventional mobile radio systems. Propagation characteristics at higher carrier frequency are therefore different from conventional cellular wireless system. With the rapid development of high-speed data services in wireless communication systems, together with the limited radio spectrum it is imperative that the effect of propagation model and system parameters on the performance of a cellular wireless network are studied in a comprehensive manner. Because propagation loss is a fundamental phenomenon which affects the performance of any wireless network.

The impact of propagation loss and system parameters on information capacity performance of land mobile cellular wireless systems has been studied and published in previous literature [6-17]. However, most of this studies have been performed in situations where carrier frequencies were below $2 \mathrm{GHz}$. Co-channel interference were considered to be from the first tier and propagation characteristics were based on the single-slope path loss propagation model.

Cox et al. in [7] performed an experiment to show the dependence of wireless signal attenuation on the antenna height, however the carrier frequency used for the experiment was $800 \mathrm{MHz}$. Green in [8], carried out signal and path loss variability analysis for small cells and concluded that path loss characteristics within smaller cell consist of two distinct regions, however the analysis was for carrier frequency below $2 \mathrm{GHz}$. Cruz-Pérez and Lara-Rodríguez in [9] studied the impact of breakpoint distance on the capacity of Manhattan like microcellular CDMA system, without considering hexagonal cell layout and interference were from the first tier only. In [10], Min and Bertoni 
studied the effect of path loss model on CDMA system design for highway microcells, however they considered a highway scenario where interference came from the first tier.

Alouini and Goldsmith studied the effect of normalized reuse distance, path loss, cell radius and shadowing on the capacity of cellular wireless network using the area spectrum efficiency [11]. However, they considered carrier frequencies $f_{c}=900 \mathrm{MHz}$ and $2 \mathrm{GHz}$, without considering carrier frequency greater than $2 \mathrm{GHz}$, effective road height and the second tier co-channel interfering cells. Har and Bertoni studied the effect of cell parameters on microcell planning, considering the first and second tier without considering carrier frequency greater than $2 \mathrm{GHz}$ [14]. Hernández et al. studied the effects of cell radius reduction and path loss model parameters on the performance of microcellular networks without the second tier co-channel interfering cells [13]. In [6], Hernández et al. studied the sensitivity of system performance to propagation parameters in LOS microcellular environment for carrier frequencies greater than $2 \mathrm{GHz}$, using outage probability for the performance analysis and considered only urban and cigar-shaped microcellular environment.

Anang et al. in $[16,17]$ studied the impact of base station antenna height and path loss exponent on the uplink information capacity of a cellular wireless system operating at carrier frequencies greater than $2 \mathrm{GHz}$, when second tier co-channel interfering cells are considered to be active. However, without considering the effect of shadowing and effective road height.

Most of the previous studies were limited to cellular wireless systems operating at the carrier frequencies $f_{c}<2 \mathrm{GHz}$. In the case where $f_{c}>2 \mathrm{GHz}$, co-channel interference were assume to be due to the first tier only and not from any other tier. This assumption was founded on large path loss exponent [18]. However, at higher carrier frequencies cell size radius reduces and path loss exponent becomes smaller, thus interference from the second tier becomes active [19]. Ge et al. in [20], reported that co-channel interference modeling and capacity analysis are of importance in the next generation mobile communication. However the interference model proposed was for multi-cell multi-antenna cellular wireless communication system.

Many propagation models have also undergone corrections in recent times, to suit other criteria's such as rough terrain areas, orchard environment, over water and wideband Digital Terrestrial Television [21-24]. Therefore, there is a need to understand the effect of system and propagation loss parameters on the performance of emerging and future cellular wireless system, which will be operating at carrier frequencies greater than $2 \mathrm{GHz}$, where cell size radii are 
smaller and second tier co-channel interfering cells are active. The main contribution of this paper is as follows.

- We proposed an improved co-channel interference model, which includes the second tier co-channel interfering cells.

- We analyzed the impact of system parameters such as antenna height and cell size on the uplink information capacity of a cellular wireless system operating at carrier frequency greater than $2 \mathrm{GHz}$, when both the first and second tier co-channel interfering cells are active.

- We studied the impact of propagation loss parameters such as shadowing component, path loss and effective road height on the uplink information capacity of a cellular wireless system operating at carrier frequency greater than $2 \mathrm{GHz}$, when both the first and second tier co-channel interfering cells are active.

The rest of the paper is organized as follows. Section 2 describes the system model for propagation, co-channel interference and user position, and outlines the basic assumptions used in modelling. In Section 3, we focus on the average area spectral efficiency of the land mobile cellular system, which we use for our information capacity performance measure. Section 4 presents some analysis and numerical results. Finally, in Section 5, some conclusions are drawn from the numerical results.

\section{PROPAGATION AND SYSTEM MODELS}

We considered a two-dimensional hexagonal microcellular wireless network, where base stations (BSs) are uniformly distributed. Cells form clusters (co-channel cell) around reference cells $\left(\mathrm{BS}_{0}\right)$ as shown in Fig. 1, and BSs are located at the centre of the cells. Each cell receives signals from all users in the system which are attenuated according to the power-law path loss and shadowing.

\subsection{Microcellular Propagation Model}

The radio environment of a cellular system is described by: (1) path loss, (2) small-scale fading and (3) large-scale fading. In this work, only path loss and shadowing are considered as we assume a scenario where an efficient antenna diversity combining system is used at the BS to eliminate the effects of multipath fading. Path loss requires an accurate modeling, because it is one of the major sources of systems performance degradation in cellular wireless system [25]. LOS propagation is assumed. Because users in the non LOS condition 


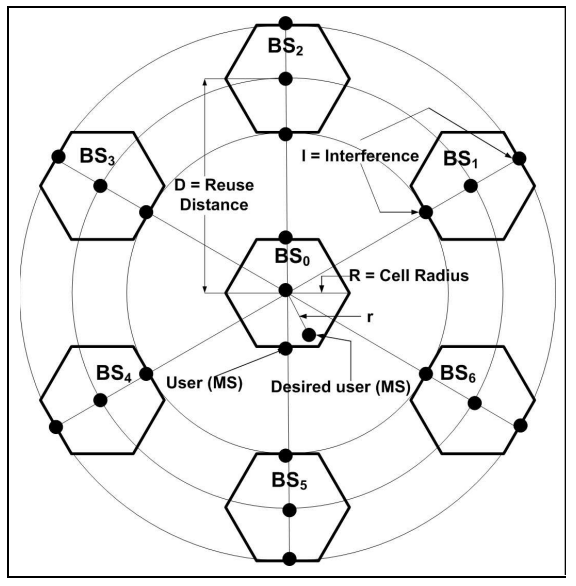

(a)

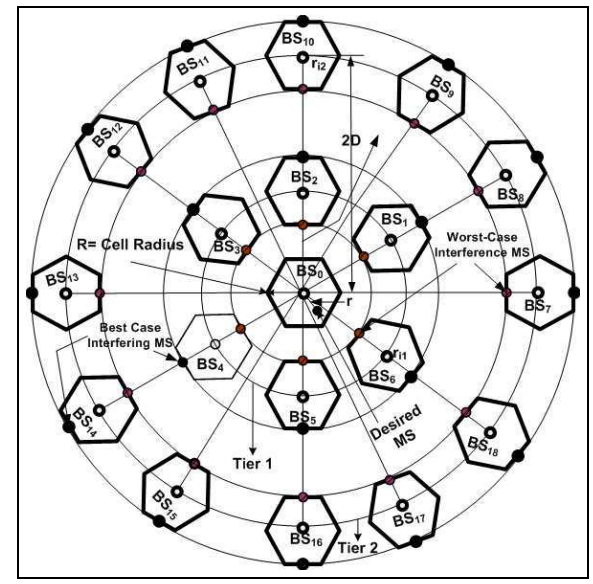

(b)

Figure 1. Hexagonal cellular site layout. Showing co-channel interfering cells. (a) Conventional cellular site layout with 6 co-channel interfering cells and reuse pattern $(N=7)$. (b) Cellular site layout with 6 and 12 co-channel interfering cells, and reuse pattern $(N=7)$.

represents less than $1 \%$ of the LOS interference, hence non LOS can be neglected [26]. Where there exist a LOS propagation between transmitting and receiving antennas radio wave propagation modeling is best done by the two-slope path loss model [27-29]. Therefore, in this paper we adopted the two-slope path loss model for our analysis and simulations, which is given by:

$$
S_{r}=\frac{K}{r^{\alpha}(1+r / g)^{\rho}} S_{t},
$$

where $K$, is the constant path loss factor, and it is the free space path loss at a reference distance, $d_{0}=1 \mathrm{~m}$. $\alpha$ is the basic path loss exponent (ranges from 2-4) for $r \leq g$ and $\rho$ the additional path loss exponent (ranges from 2-8) for $r>g$. The parameter $r[\mathrm{~m}]$ is the separation distance between transmitter and receiver, $S_{r}[\mathrm{~W}]$ the received signal power, and $S_{t}[\mathrm{~W}]$ the transmitted signal power. The parameter $g[\mathrm{~m}]$ is the breakpoint of the path loss curve and is given by $g=4 h_{b} h_{m} / \lambda_{c}$, where $h_{b}[\mathrm{~m}]$ is BS antenna height, $h_{m}[\mathrm{~m}]$ the mobile station (MS) antenna height, and $\lambda_{c}[\mathrm{~m}]$ the microwave carrier frequency wavelength [30]. We use typical values in $[4,31,32]$ for the analysis in this paper. Table 1 shows that as $f_{c}$ increases $g$ becomes longer, likewise when $h_{b}$ increases.

Figure 2, shows the average received signal power given by (1) 
Table 1. Calculated breakpoint distance for different carrier frequencies.

\begin{tabular}{|c|c|c|c|c|}
\hline $\begin{array}{c}\text { Carrier } \\
\text { frequencies }\left(f_{c}\right)\end{array}$ & $\lambda_{c}=\frac{3 * 10^{8}}{f_{c}}$ & $h_{m}$ & $\begin{array}{c}g \text { for } \\
h_{b}=10 \mathrm{~m}\end{array}$ & $\begin{array}{c}g \text { for } \\
h_{b}=15 \mathrm{~m}\end{array}$ \\
\hline $900 \mathrm{MHz}$ & $0.33 \mathrm{~m}$ & $1.8 \mathrm{~m}$ & $216 \mathrm{~m}$ & $324 \mathrm{~m}$ \\
\hline $2 \mathrm{GHz}$ & $0.15 \mathrm{~m}$ & $1.8 \mathrm{~m}$ & $480 \mathrm{~m}$ & $720 \mathrm{~m}$ \\
\hline $3.35 \mathrm{GHz}$ & $0.09 \mathrm{~m}$ & $1.8 \mathrm{~m}$ & $804 \mathrm{~m}$ & $1206 \mathrm{~m}$ \\
\hline $8.45 \mathrm{GHz}$ & $0.035 \mathrm{~m}$ & $1.8 \mathrm{~m}$ & $2028 \mathrm{~m}$ & $3042 \mathrm{~m}$ \\
\hline $15.75 \mathrm{GHz}$ & $0.019 \mathrm{~m}$ & $1.8 \mathrm{~m}$ & $3780 \mathrm{~m}$ & $5670 \mathrm{~m}$ \\
\hline
\end{tabular}

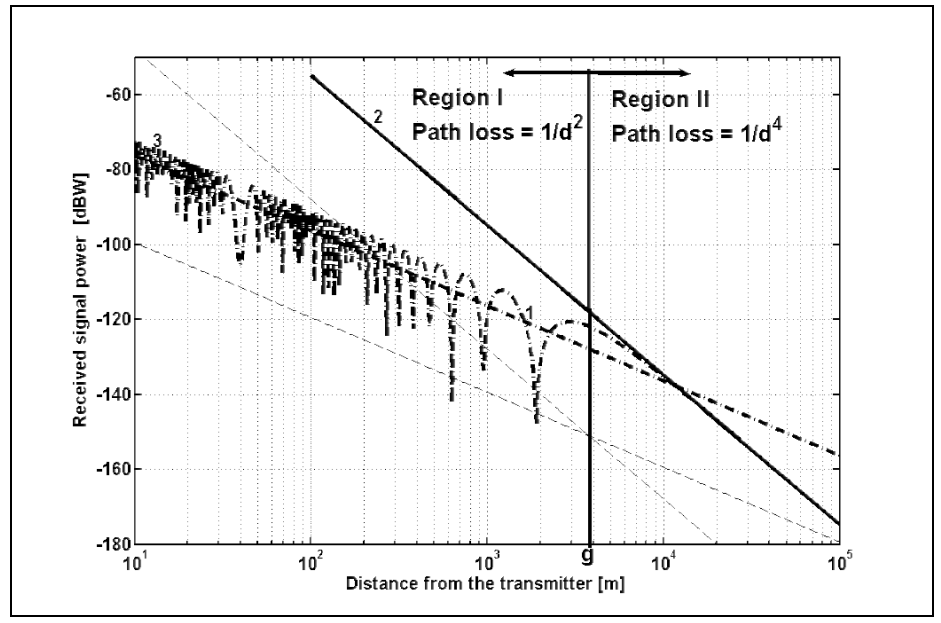

1 Free Space Path Loss Model 3 Two Ray Model

2 Power falls off $\propto 1 /(\text { distance })^{4}$

Figure 2. Two-slope path loss model; received signal strength vs. distance, showing breakpoint distance, $g$ for line of sight propagation. (Transmit power, $S_{t}=1 \mathrm{~W}$, transmit and receiver antenna gains; $G_{t}$ and $G_{r}=0 \mathrm{~dB}$, path loss exponent; $\alpha=2$, extra path loss exponent, $\rho=4$, base and mobile station antenna heights; $h_{b}=15 \mathrm{~m}$ and $h_{m}=1.8 \mathrm{~m}$, reference distance $d_{0}=1 \mathrm{~m}$ and carrier frequency, $f_{c}=15.75 \mathrm{GHz}$ carrier frequency.

plotted as a function of distance for MS and BS antenna height of 1.8 and $15 \mathrm{~m}$, and carrier frequency of $15.75 \mathrm{GHz}$. The figure shows that for the path loss, two regions may be distinguished, which are separated by the breakpoint $g$. Before $g$ the path loss is similar to free-space path loss $\left(\right.$ path loss decreases $\left.\propto 1 /(\text { distance })^{2}\right)$. The path loss after $g$ 
decreases in inverse proportion to the fourth power of distance (path loss decreases $\left.\propto 1 /(\text { distance })^{4}\right)$.

In the vicinity of high obstacles particularly in urban microcellular systems the propagation is also affected by the shadowing of the LOS path from the terrain, buildings and trees. Shadowing is modeled as lognormal distribution [33]. The Probability Distribution Function (PDF) of the slowly varying received signal power is thus given by the standard lognormal expression as

$$
p(P)=\frac{\xi}{\sqrt{2 \pi} \sigma_{P} P} \exp \left(-\frac{\left(\xi \ln (P)-\mu_{P}\right)^{2}}{2 \sigma_{P}^{2}}\right), \quad P \geq 0
$$

where $\xi=10 / \ln 10 \approx 4.3429$ is a scaling constant, and $\mu_{P}[\mathrm{~dB}]$ and $\sigma_{P}[\mathrm{~dB}]$ are the mean and standard deviation of $\xi \ln (P)$.

\subsubsection{Modified Breakpoint Distance}

It was concluded in [27], that at higher carrier frequencies greater than $2 \mathrm{GHz}(3.35,8.45$ and $15.75 \mathrm{GHz})$, for LOS path loss characterization in terms of breakpoint distance, the breakpoint distance was found to be different from that predicted by the first Fresnel zone model in [30]. The breakpoint distance $g_{h}$, for path loss characterization at carrier frequencies greater than $2 \mathrm{GHz}$ is therefore given by [4], as

$$
g_{h}=\frac{4\left(h_{b}-h\right) \times\left(h_{m}-h\right)}{\lambda_{c}}, \quad\left(h<h_{m}\right)
$$

where $h$ is the effective road height, which is less than $h_{m}$. The difference between $g$ for carrier frequencies less than $2 \mathrm{GHz}$ and $g_{h}$ for carrier frequency greater than $2 \mathrm{GHz}$ is the result of change in $h$, which is caused by vehicles, pedestrians, and other objects on the road. The effective road height $h$, therefore depends on the traffic on the road, and it is estimated by minimizing the difference between the estimated and theoretical breakpoint distances. For light vehicular traffic $h$, is between $0.23-0.74[\mathrm{~m}]$, and for heavy vehicular traffic between 1.29$1.64[\mathrm{~m}][32]$.

Table 2. Breakpoint distance for light vehicular traffic.

\begin{tabular}{|c|c|c|c|c|c|}
\hline $\begin{array}{c}\text { Carrier } \\
\text { frequencies }\left(f_{c}\right)\end{array}$ & $\lambda_{c}=\frac{3 * 10^{8}}{f_{c}}$ & $h_{m}$ & $h$ & $\begin{array}{c}g_{h} \text { for } \\
h_{b}=10 \mathrm{~m}\end{array}$ & $\begin{array}{c}g \text { for } \\
h_{b}=15 \mathrm{~m}\end{array}$ \\
\hline $3.35 \mathrm{GHz}$ & $0.09 \mathrm{~m}$ & $1.8 \mathrm{~m}$ & 0.3 & $649.9000 \mathrm{~m}$ & $984.9000 \mathrm{~m}$ \\
\hline $8.45 \mathrm{GHz}$ & $0.035 \mathrm{~m}$ & $1.8 \mathrm{~m}$ & 0.3 & $1639.3 \mathrm{~m}$ & $2484.3 \mathrm{~m}$ \\
\hline $15.75 \mathrm{GHz}$ & $0.019 \mathrm{~m}$ & $1.8 \mathrm{~m}$ & 0.3 & $3055.5 \mathrm{~m}$ & $46305 \mathrm{~m}$ \\
\hline
\end{tabular}


Kitao and Ichitsubo in [5] stated that at higher carrier frequencies, because $\lambda$ ranges from 2 to $9 \mathrm{~cm}$, which are smaller compared to the size of vehicles. Therefore it can be assumed that the surface of the road becomes uniformly higher and reflection mainly caused by vehicles can be handled by $h$. Experimental results in [4] show that the breakpoint distance measured at night is more than that measured during the day, because at night there is a lower amount of traffic on the road. Table 2 shows $g_{h}$ for different $f_{c}$ and $h_{b}$ for light vehicular traffic. Table 3 shows $g_{h}$ for different $f_{c}$ and $h_{b}$ for heavy vehicular traffic. Figure 3 reveals that as the effective road height increases the

Table 3. Breakpoint distance for heavy vehicular traffic.

\begin{tabular}{|c|c|c|c|c|c|}
\hline $\begin{array}{c}\text { Carrier } \\
\text { requencies } \\
\left(f_{c}\right)\end{array}$ & $\lambda_{c}=\frac{3 * 10^{8}}{f_{c}}$ & $h_{m}$ & $h$ & $\begin{array}{c}g_{h} \text { for } \\
h_{b}=10 \mathrm{~m}\end{array}$ & $\begin{array}{c}g \text { for } \\
h_{b}=15 \mathrm{~m}\end{array}$ \\
\hline $3.35 \mathrm{GHz}$ & $0.09 \mathrm{~m}$ & $1.8 \mathrm{~m}$ & 1.29 & $198.4138 \mathrm{~m}$ & $312.3138 \mathrm{~m}$ \\
\hline $8.45 \mathrm{GHz}$ & $0.035 \mathrm{~m}$ & $1.8 \mathrm{~m}$ & 1.29 & $500.4766 \mathrm{~m}$ & $787.7766 \mathrm{~m}$ \\
\hline $15.75 \mathrm{GHz}$ & $0.019 \mathrm{~m}$ & $1.8 \mathrm{~m}$ & 1.29 & $932.8410 \mathrm{~m}$ & $1468.3 \mathrm{~m}$ \\
\hline
\end{tabular}

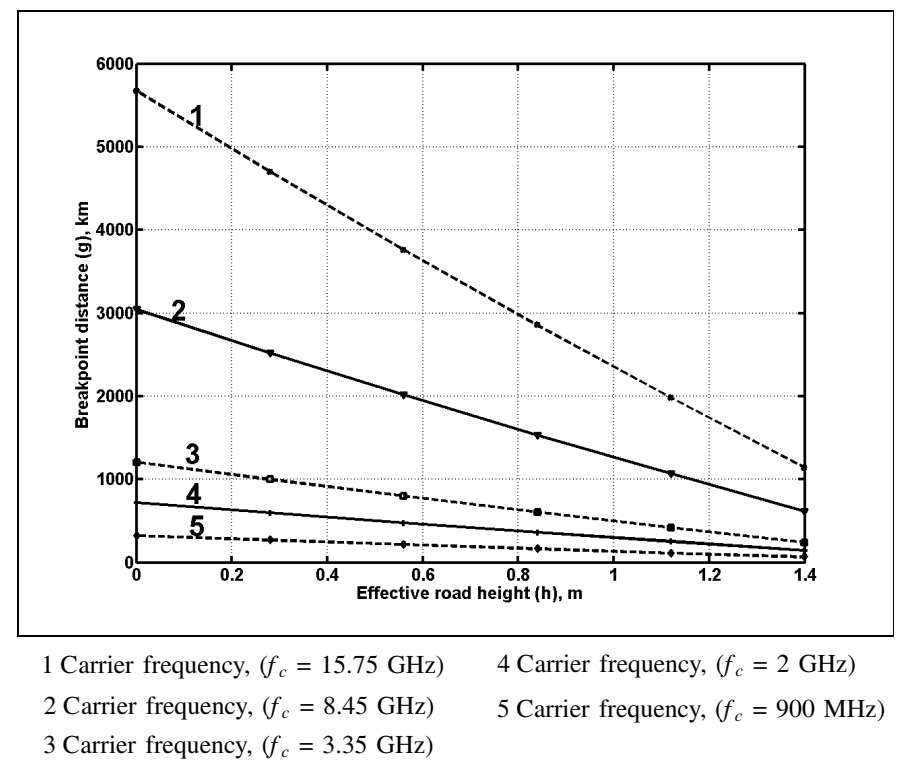

Figure 3. Breakpoint distance, $g$ vrs. effective road height, $h$ for different carrier frequencies $f_{c}$. BS and MS antenna height; $h_{b}=15 \mathrm{~m}$ and $h_{m}=1.8 \mathrm{~m}$. 
breakpoint distance becomes shorter. It also shows that as carrier frequency increase breakpoint distance becomes longer.

\subsection{Improved Co-channel Interference Model}

The first and second tiers of co-channel cells are considered in interference generation, unlike the existing model ([11]), where only first tier co-channel cells are considered. The desired MS is located in the central cell and the interfering mobiles are in cells in the first and second tiers. Fig. 1(a) shows a conventional cellular system layout with 6 co-channel interfering cells surrounding the desired $\mathrm{BS}\left(\mathrm{BS}_{0}\right)$. Fig. 1(b) shows a cellular layout with the first 6 co-channel interfering cells and the second 12 co-channel interfering cells surrounding the desired $\mathrm{BS}, \mathrm{BS}_{0}$.

To simplify the analysis the following assumptions have been made in the co-channel interference model. First the system is considered to be interference-limited, with thermal noise power negligible relative to the co-channel interference power [34]. Thus, the ratio of carrier to noise $C N R$, reduces to the carrier-to-interference power ratio $C I R$. All inter-channel interference are considered to be negligible [34]. All BSs are assumed to transmit the same power.

Reference [11], provides a formula for calculating the uplink desired user CIR for traditional cellular wireless communication systems. Now it is reported in [35] that the uplink interference at a BS is the non-coherent sum of interference signals from the users served by the BS and the users served by other BSs. Likewise the desired user $C I R, \gamma$, is defined as the ratio of the average received signal power from a MS at a distance $r[\mathrm{~m}]$ from the desired BS to the sum of interfering received signal power. Thus, the improved desired user $C I R, \gamma$, can be written as follows:

$$
\gamma=\frac{S_{r}}{\overline{S_{I}}}=\frac{S_{r}(r)}{\sum_{f i=1}^{N_{F I}} S_{f i}\left(r_{f i}\right)+\sum_{s i=1}^{N_{S I}} S_{s i}\left(r_{s i}\right)}
$$

where $S_{r}[\mathrm{~W}]$ is the average received signal power level and $S_{I}[\mathrm{~W}]$ the sum of interfering received signal power. $N_{F I}$ and $N_{S I}$ are the total number of co-channel interfering cells in regions I \& II (refer to Fig. 2), which are assumed to be interfering cells in the first and second tier. $S_{f i}[\mathrm{~W}]$ and $S_{s i}[\mathrm{~W}]$ are the average received signal power level from the $i$ th interfering MSs' at distances $r_{f i}$ and $r_{s i}$ in the regions I \& II from the desired BS. 


\subsection{Traffic Distribution}

The cell shape is approximated by a circle of radius $R$. All MSs' (desired and interfering) are assumed to be uniformly and independent distributed in their cells. MSs' are also assumed to be located in the far field region. The probability distribution function (PDF) of a MS location relative to its $\mathrm{BS}$ in polar co-ordinate is given by:

$$
p_{r, \theta}(r, \theta)=\frac{\left(r-R_{0}\right)}{\pi\left(R-R_{0}\right)^{2}} ; \quad R_{0} \leq r \leq R, 0 \leq \theta \leq 2 \pi .
$$

$R_{0}$ corresponds to the closet distance that a MS can be from the BS antenna, (to be in the far field region) and is approximately $20 \mathrm{~m}$ for microcellular systems.

\section{AREA SPECTRAL EFFICIENCY}

The average area spectral efficiency (ASE) measured in $\left[\mathrm{bits} / \mathrm{s} / \mathrm{Hz} / \mathrm{km}^{2}\right]$ is defined as the achievable sum rate (of all users in a cell uplink) per unit bandwidth per unit area and is given by [11] as:

$$
A_{e}=\frac{\sum_{k=1}^{N_{s}} C_{k}}{\pi \omega(D / 2)^{2}}
$$

where $\omega$ is the total bandwidth allocated to each cell, $D$ the reuse distance, and $N_{s}$ the total number of active serviced channels per cell. The achievable sum rate $C_{k}$ [bits/sec] is the Shannon capacity of the $k$ th user, which depends on $\gamma$, the received carrier to interference power ratio $C I R$ of that user, and $\omega_{k}$ the bandwidth allocated to the user. The Shannon capacity formula $(C=\omega \log (1+C I R))$ assumes interference has Gaussian characteristics. Because both the interference and signal power of the $k$ th user vary with mobiles locations and propagation conditions, $\gamma$ varies with time, therefore the average channel capacity of the $k$ th user is given by [11] as:

$$
\left\langle C_{k}\right\rangle=\omega_{k} \int_{0}^{+\infty} \log _{2}(1+\gamma) p_{\gamma}(\gamma) d \gamma,
$$

where $p_{\gamma}(\gamma)$, is the probability distribution function (PDF) of the average mean $C I R(\gamma)$ of the $k$ th user.

The transmission rate is assumed to be continuously adapted relative to the $C I R$ in such a manner that the BER goes to zero asymptotically. In (7) assuming that all users are assigned the same 
bandwidth, $\left\langle C_{k}\right\rangle=(\langle C\rangle)$, becomes the same for all users, therefore $\left\langle A_{e}\right\rangle$ can be written as:

$$
\left\langle A_{e}\right\rangle=\frac{4 N_{s}\langle C\rangle}{\pi \omega D^{2}}=\frac{4 N_{s}\langle C\rangle}{\pi \omega R_{u}^{2} R^{2}},
$$

where $R_{u}$ is defined as the normalized reuse distance and is given by the ratio of reuse distance and cell radius $(D / R)$. For a FDMA systems, where all users are allocated the same bandwidth $\omega_{k}=\omega_{0}=\omega / N_{s}$. Substituting $\omega / N_{s}$ in (7) followed by substitution into (8) yields:

$$
\left\langle A_{e}\right\rangle=\frac{4}{\pi R_{u}^{2} R^{2}} \int_{0}^{+\infty} \log _{2}(1+\gamma) p_{\gamma}(\gamma) d \gamma
$$

For TDMA systems, the total bandwidth $\omega$ is allocated to one user per time slot, thus $N=1$, and $\omega_{k}=\omega$. Substituting this in (8), shows that TDMA systems have the same $A S E$ as FDMA systems.

\section{SYSTEM AND PROPAGATION LOSS PARAMETERS IMPACT ANALYSIS}

In this section, we compute the effect of both system and propagation loss parameters on the $A S E$ of a smaller cell size radius cellular wireless system operating at microwave carrier frequency greater than $2 \mathrm{GHz}$, in the presence of the first and second tier co-channel interfering cells. The analysis applies to a TDMA system, and is based on fully loaded non-sectorized cellular systems ignoring multipath fading. Although there is an excessive demand to broadcast (downlink) high speed data in most emerging communication services, we focus on the uplink between a MS and an intended BS. However, our analysis can be extended to the downlink of a cellular wireless system. The analysis presented in this section considers each BS to have an omnidirectional antenna; however, it is straightforward to extend this to the case of sectorization antennas.

\subsection{Effect of Path Loss}

As users are randomly located in their respective cells, the desired user $C I R \gamma$, becomes a random variable depending on the position of the $\left(N_{T I}+1\right)$ desired and interfering MSs, where $N_{T I}$ is the sum of $N_{F I}$ and $N_{S I}$. The problem is reduced from $\left(N_{T I}+1\right)$ dimensions to 1 dimension to simplify the analysis by computing $\gamma$ the corresponding area spectrum efficiency for the average case interference configuration. With no power control all the $N_{F I}$ and $N_{S I}$, co-channel interferes are at the centre of their respective cells (average case interference), at 
distance $r_{f i}=D[\mathrm{~m}]$ and $r_{s i}=2 D[\mathrm{~m}]$ from the desired mobile's BS, where $D$ denote the distance between $\mathrm{BS}_{0}$ and first tier BS and $2 \mathrm{D}$ the distance between $\mathrm{BS}_{0}$ and second tier $\mathrm{BS}$ [35]. Note that power control is essential for direct sequence CDMA systems. However in this paper we consider the most representative cellular technology, which is TDMA based. Fig. 1(b) shows the cellular system configuration. Assuming the transmitted power of all users are the same and substituting (1) into (4) yields:

$$
\begin{aligned}
& \gamma\left(r, N_{F I}, N_{S I}\right) \\
= & \frac{\overline{S_{r}}(r)}{\sum_{f i=1}^{N_{F I}} \overline{S_{f i}}\left(r_{f i}\right)+\sum_{s i=1}^{N_{s i}} \overline{S_{s i}}\left(r_{s i}\right)} \\
= & \frac{r^{-\alpha}(1+r / g)^{-\rho}}{\sum_{f i=1}^{N_{F I}} r_{f i}^{-\alpha}\left(1+r_{f i} / g\right)^{-\rho}+\sum_{s i=1}^{N_{S I}} r_{s i}^{-\alpha}\left(1+r_{s i} / g\right)^{-\rho}} \\
= & \frac{r^{-\alpha}(1+r / g)^{-\rho}}{\sum_{f i=1}^{N_{F I}} R R u^{-\alpha}\left(1+R R_{u} / g\right)^{-\rho}+\sum_{s i=1}^{N_{S I}}\left(2 R R_{u}\right)^{-\alpha}\left(1+\left(2 R R_{u}\right) / g\right)^{-\rho}} \\
= & \left(\frac{2^{\alpha} \cdot N_{F I}+N_{S I}}{N_{F I} \cdot N_{S I}}\right) \cdot\left(\frac{R_{u} R}{r}\right)^{\alpha}\left(\frac{g+2 R_{u} R}{g+r}\right)^{\rho},
\end{aligned}
$$

where $R_{u}$ is the normalized reuse distance and $R$ is the cell size radius. Since $\gamma$ is a function of $r$, the desired user capacity is given by:

$$
C\left(N_{T I}, r\right)=B_{o} \log _{2}\left(1+\gamma\left(N_{F I}, N_{S I}, r\right)\right) \text {. }
$$

for $\gamma$ given by (10). Substituting (11) in (8) yields the $A S E$ conditioned on the desired mobile position $r$, for a fully-loaded system. Integrating (11) over the desired user's position PDF (5) yields the average $A S E$ for the average interference configuration as:

$$
\left\langle A_{e}\left(N_{T I}\right)\right\rangle=\frac{4}{\pi R_{u}^{2} R^{2}} \int_{R_{0}}^{R} \log _{2}\left(1+\gamma\left(N_{F I}, N_{S I}, r\right) p_{r}(r) d r .\right.
$$

It is clear from (12), that the average $A S E$ depends on the area mean, $C I R$ which is a function of random locations of the MS, which makes it mathematically intractable to solve. A computer simulation is therefore used to solve it.

\subsection{Effect of Shadowing}

In this subsection, we compute the effect of shadowing on uplink information capacity of a cellular wireless system operating at higher 
microwave carrier frequencies greater than $2 \mathrm{GHz}$ and smaller cell size radius when both the first and second tier co-channel interfering cell are active. We consider a fully loaded cellular system where both desired and interfering users are affected by lognormal shadowing superimposed on path loss. This case do apply to BS radio receivers which are able to average out the fast multipath fading, in this case the system only react to lognormal channel variation. All assumption made early in this paper still holds unless otherwise stated.

\subsection{Analyses}

We assumed the desired user's signal to be lognormally shadowing according to (2), (Subsection 2.1) with mean power $\mu_{P}$ and standard deviation $\sigma_{P}$. There are $N_{T I}$ mutually independent lognormally shadowed co-channel interferes (independent identically distributed (i.i.d.)), each with mean $\mu_{i}$ and standard deviation $\sigma_{i}$.

\subsubsection{Probability Distribution Function of Desired User Carrier-to-interference Ratio}

The total interference power $S_{I}$ is the sum of $N_{T I}$ i.i.d. lognormally distributed random variables $(\mathrm{RV})$ in the first and second tier $\left(N_{F I}\right.$ and $\left.N_{S I}\right)$. Generally closed-form expressions for the PDF of lognormal sum are not known, however it has been accepted that it can be approximated by another lognormal distribution. In this work, we use the Fenton-Wilkinson method [33], because of its simplicity. Using this method, the logarithmic mean $\mu_{P_{I}}$ and logarithmic variance $\sigma_{P_{I}}$ of $S_{I}$ can be approximated by matching the first- and second-order moments as follows:

$$
\mu_{P_{I}}=\mu_{I}+\xi \ln \left(N_{T I}\right)+\frac{\sigma_{I}^{2}}{2 \xi}-\frac{\xi}{2} \ln \left(\frac{\left(N_{T I}-1\right)+e^{\sigma_{I}^{2} / \xi^{2}}}{N_{T I}}\right)
$$

where $N_{T I}$ is the sum of co-channel interfering cells in the first and second tier, which in this case is 18. Thus (13) becomes

$$
\mu_{P_{I}}=\mu_{I}+\xi \ln (18)+\frac{\sigma_{I}^{2}}{2 \xi}-\frac{\xi}{2} \ln \left(\frac{17+e^{\sigma_{I}^{2} / \xi^{2}}}{18}\right)
$$

and

$$
\sigma_{P_{I}}^{2}=\xi^{2} \ln \left(\frac{17+e^{\sigma_{I}^{2} / \xi^{2}}}{18}\right)
$$

Since the ratio of two lognormal RV's is also a lognormal RV, it follows that the PDF of the desired MS CIR $\gamma$ can be approximated by a 
lognormal PDF

$$
p_{\gamma_{d}}\left(\gamma_{d}\right)=\frac{\xi}{\sqrt{2 \pi} \sigma_{\gamma_{d}} \gamma_{d}} \exp \left(-\frac{\left(\xi \ln \left(\gamma_{d}\right)-\mu_{\gamma_{d}}\right)^{2}}{2 \sigma_{\gamma_{d}}^{2}}\right), \quad \gamma_{d} \geq 0
$$

whose logarithmic mean and variance are

$$
\begin{aligned}
& \mu_{\gamma_{d}}=\mu_{P}-\mu_{P_{I}} \\
& \sigma_{\gamma_{d}}=\sigma_{P}^{2}+\sigma_{P_{I}}^{2}
\end{aligned}
$$

Now inserting (16) in (7) yields the desired MS's average capacity as follows:

$$
\langle C\rangle=\frac{W_{o} \log _{2}(e) \xi}{\sqrt{2 \pi} \sigma_{\gamma_{d}}} \int_{0}^{+\infty} \frac{\ln \left(1+\gamma_{d}\right)}{\gamma_{d}} \exp \left(-\frac{\left(\xi \ln \left(\gamma_{d}\right)-\mu_{\gamma_{d}}\right)^{2}}{2 \sigma_{\gamma_{d}}^{2}}\right) d \gamma_{d}
$$

Substituting (19) in (8) yields the $A S E$ for the average case interference configuration in a shadowing environment as

$$
A_{e}(r)=\frac{4 C(r)}{\pi W_{o} R_{u}^{2} R^{2}},
$$

The mean in (17), is computed as follows

$$
\begin{aligned}
\mu_{\gamma_{d}}= & \xi \ln \left[2^{\alpha}\left(\frac{R_{u} R}{r}\right)^{\alpha}\left(\frac{g^{2}+3 g R_{u} R+2 R_{u}^{2} R^{2}}{g+r}\right)^{\rho}\right. \\
& \left.\cdot \frac{1}{2^{\alpha}\left(g+2 R_{u} R\right)^{\rho}+\left(g+R_{u} R\right)^{\rho}}\right]-\xi \ln (18)+\frac{\sigma_{P I}^{2}-\sigma_{I}^{2}}{2 \xi}
\end{aligned}
$$

and $\sigma_{\gamma_{d}}^{2}$ is given by (18). As the expressions in (20) is conditioned on the desired MS position, the site specific average $A S E$ at a distance $r$ and angle $\theta$ from the central base station, $\mathrm{BS}_{0}$ is given by:

$$
\left\langle A_{e}\right\rangle=\frac{4}{\pi R_{u}^{2} R^{2}} \int_{R_{0}}^{R} \log _{e}(e)\left[\frac{\mu_{\gamma}}{\xi}+\exp \left(-\frac{\mu_{\gamma_{d}}}{\xi}+\frac{\sigma_{\gamma_{d}}^{2}}{2 \xi^{2}}\right)\right] p_{r}(r) d r
$$

Due to the random location of MSs in their cells, (22) is mathematical intractable to solve explicitly.

\subsection{Computer Simulations}

As $\left\langle A_{e}\right\rangle$ appears to be mathematically intractable to solve explicitly analytically, a Monte Carlo simulation is used to estimate it. The basic parameter used for the simulations are summarized in Table 4, and Fig. 4, shows a simplified flowchart for the simulation. The simulation methodology is as follows. 


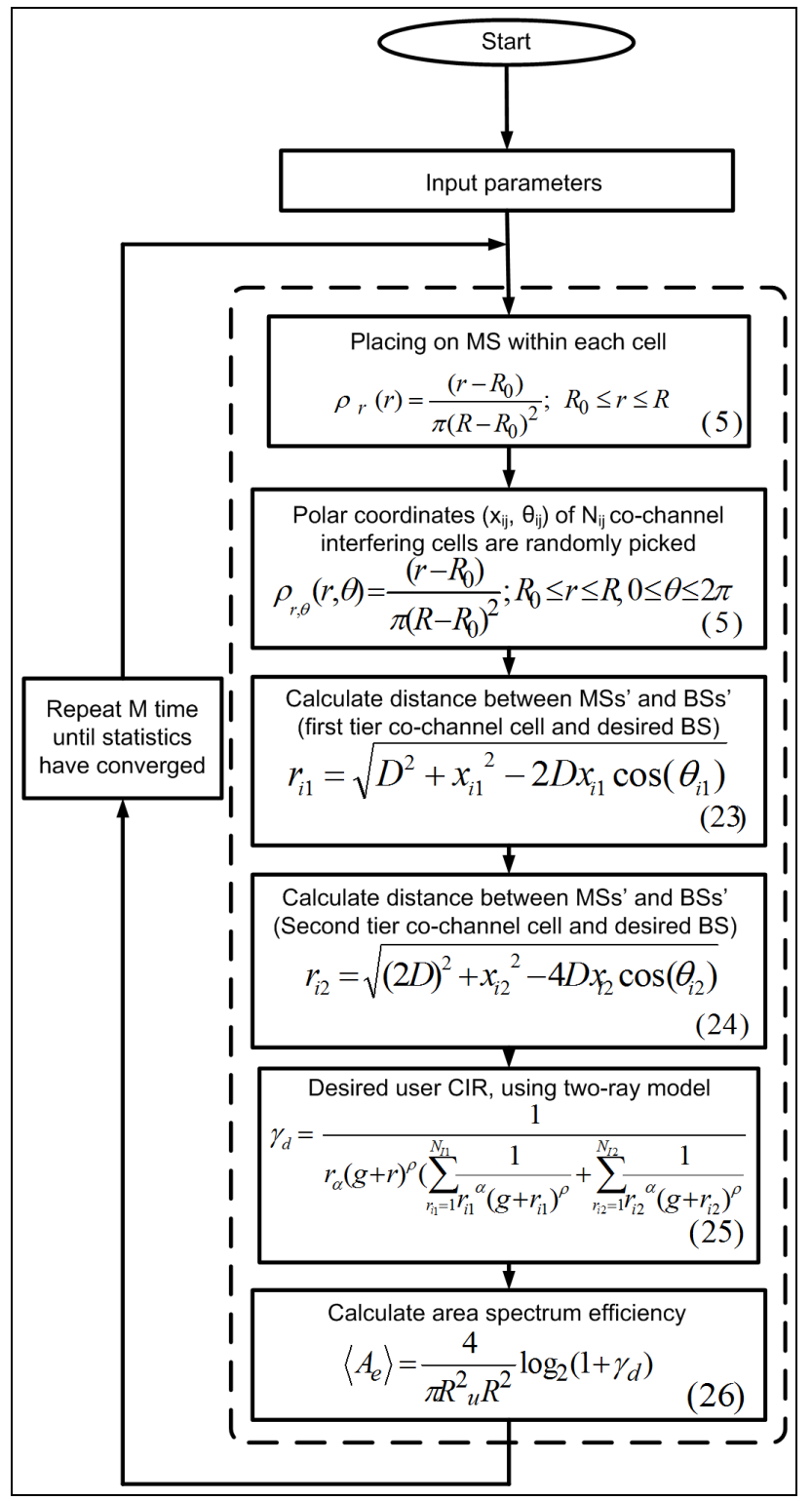

Figure 4. ASE simulation flowchart for distance-dependent path loss.

\subsubsection{Path Loss}

I. One MS is randomly located within each cell, according to uniform distribution as described in Subsection 2.3 of Section 2. 
Table 4. Simulation parameters.

\begin{tabular}{|c|c|}
\hline Parameters & Values \\
\hline Cell radius $R$ & 100 to $1000 \mathrm{~m}$ \\
\hline Path loss exponent $(\alpha)$ & $2,2.5,2.8$ and 3 \\
\hline Additional path loss exponent $(\rho)$ & 4 \\
\hline Reference distance $\left(d_{0}\right)$ & $1 \mathrm{~m}$ \\
\hline Path loss constant $(K)$ & $20 \log _{10}\left(\lambda_{c} / 4 \pi d_{0}\right) \mathrm{dB}$ \\
\hline MS transmission power $\left(S_{t}\right)$ & $1 \mathrm{~W}$ \\
\hline BS antenna height $\left(h_{b}\right)$ & 10 and $15 \mathrm{~m}[31]$ \\
\hline MS antenna height $\left(h_{m}\right)$ & $1.8 \mathrm{~m}[31]$ \\
\hline Mobile Distribution & Uniform and Random \\
\hline Interference & First and Second Tiers \\
\hline Carrier frequencies $f_{c}$ & $0.9,2,3.35,8.45$ \\
& and $15.75 \mathrm{GHz}[4,11]$ \\
\hline Frequency reuse factor & $4[11]$ \\
\hline
\end{tabular}

II. The polar coordinates $\left(x_{f i}, \theta_{f i}\right.$ and $\left.x_{s i}, \theta_{s i}\right)$ of the $N_{F I}$ and $N_{S I}$ co-channel interferers are randomly picked according to (5).

III. We represent the location of the MSs and the BSs using rectangular and polar coordinate system. Distances between MSs and BSs are computed, and finally distances between desired $\mathrm{BS}_{0}$ with respect to the $i$ th interfering MSs (see Fig. 5) are computed. The distance $r_{f i}$ for each co-channel interferer from the first tier to the desired $\mathrm{BS}$ is calculated as,

$$
r_{f i}=\sqrt{D^{2}+x_{f i}^{2}-2 D x_{f i} \cos \left(\theta_{f i}\right)}
$$

IV. The distance $r_{s i}$ for each co-channel interferer from the second tier to the desired BS is calculated as:

$$
r_{s i}=\sqrt{(2 D)^{2}+x_{s i}^{2}-4 D x_{s i} \cos \left(\theta_{s i}\right)}
$$

V. The dual-slope path loss model (1), is used to calculate the area mean power of the desired user and interfering mobiles in the first and second tier of co-channel cells $\left(S_{d}, S_{f i}\right.$ 's and $S_{s i}$ 's), therefore $C I R$ is calculated as.

$$
\gamma=\frac{1}{r^{\alpha}(g+r)^{\rho}\left(\sum_{r_{f i}=1}^{N_{F I}} \frac{1}{r_{f i}^{\alpha}\left(g+r_{f i}\right)^{\rho}}+\sum_{r_{s i}=1}^{N_{S I}} \frac{1}{r_{s i}^{\alpha}(g+r i 2)^{\rho}}\right)}
$$




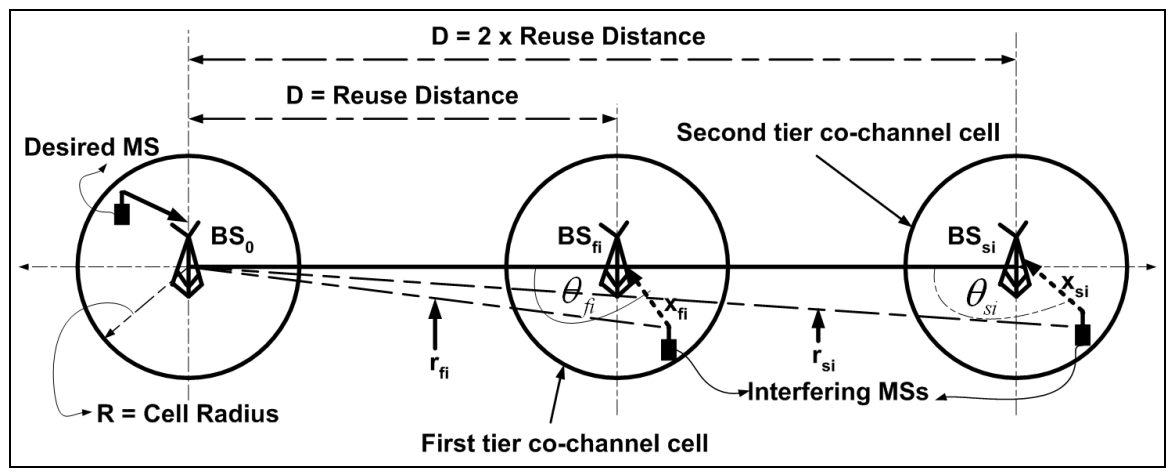

Figure 5. Geometry of desired MS and interfering MSs in two cochannel cells.

VI. The ASE, $A_{e}$ is calculated as:

$$
A_{e}=\frac{4}{\pi R_{u}^{2} R^{2}} \log _{2}(1+\gamma)
$$

Repeating the proceed above (from steps 1-6) 100000 times. The value of $\left\langle A_{e}\right\rangle$ was estimated by taking the average of all the observations of $A_{e}$ as given by (26).

\subsubsection{Shadowing}

For the case of shadowing the algorithm described in Section 4.4.1 is change from step 5) to incorporate the effect of shadowing as follows:

VII. The $N_{T I}+1$ area mean powers $\left(\mu_{P}\right.$ and $\left.\mu_{i^{\prime} s}\right)$ at the considered BS are calculated using the dual-slope path loss model (1).

VIII. The instantaneous received power from the desired and interfering mobiles $\left(S_{d}, S_{f i}\right.$ 's and $S_{s i}$ 's) are generated randomly according to a lognormal distribution (2) with area means $\mu_{P}$ and $\mu_{i^{\prime} s}$, and standard deviations $\sigma_{P}$ and $\sigma_{I}$.

We repeat the proceed for the shadowing case 1000000 times to average out the additional effect of shadowing to obtain the same degree of accuracy for the average $A S E$.

\subsection{Numerical Results}

This section present Numerical results. The aim of the results presented in this section is to make clear the influence of system and propagation loss parameters on the performance of emerging and 
future cellular wireless systems, rather than the mathematical analysis itself. It is important to note that the main contributions of our work are the findings we obtained by analyzing the impact of system and propagation loss parameters on the information capacity performance of cellular wireless system operating at higher carrier frequency $f_{c}>$ $2 \mathrm{GHz}$ and smaller cell size radius, when the first and second tier cochannel interfering cells are active. Our simulation compares result for the conventional interference model presented in [11] (first tier co-

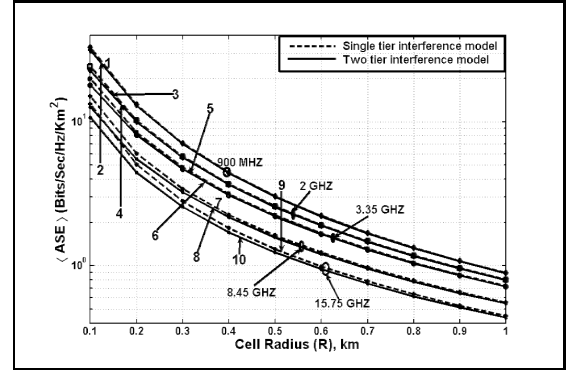

(a)

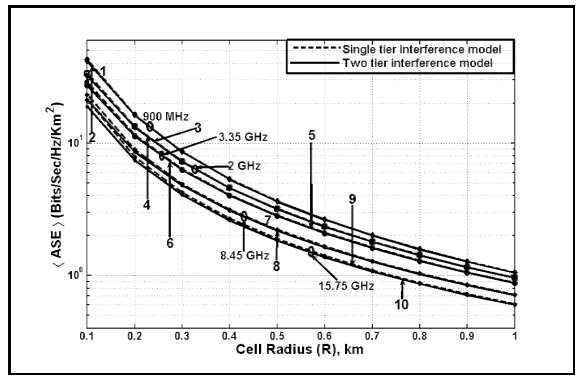

(c)

1 Single tier co-channel interfering model $\left(f_{c}=900 \mathrm{MHz}\right)$ 2 Two tier co-channel interfering model $\left(f_{c}=900 \mathrm{MHz}\right)$ 3 Single tier co-channel interfering model $\left(f_{c}=2 \mathrm{GHz}\right)$ 4 Two tier co-channel interfering model $\left(f_{c}=2 \mathrm{GHz}\right)$ 5 Single tier co-channel interfering model $\left(f_{c}=3.35 \mathrm{GHz}\right)$

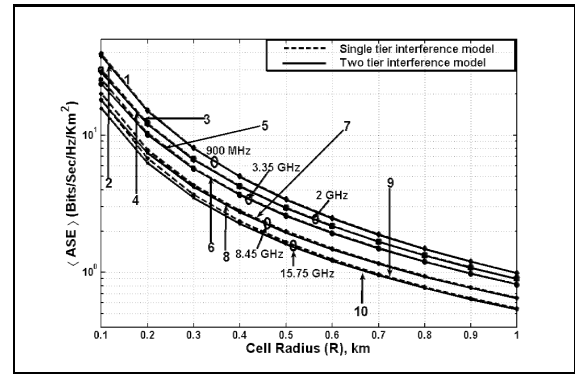

(b)

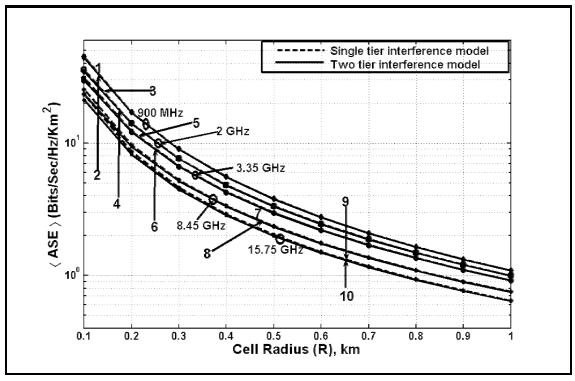

(d)

6 Two tier co-channel interfering model $\left(f_{c}=3.35 \mathrm{GHz}\right)$

7 Single tier co-channel interfering model $\left(f_{c}=8.45 \mathrm{GHz}\right)$

8 Two tier co-channel interfering model $\left(f_{c}=8.45 \mathrm{GHz}\right)$

9 Single tier co-channel interfering model $\left(f_{c}=15.75 \mathrm{GHz}\right)$ 10 Two tier co-channel interfering model $\left(f_{c}=15.75 \mathrm{GHz}\right)$

Figure 6. Average uplink area spectral efficiency versus cell radius for different path loss exponents, $\alpha$, and carrier frequencies $f_{c}$. (Fullyloaded system with 6 and 12 co-channel interfering cells in first and second tier $N_{F I}=6$ and $N_{S I}=12$; extra path loss exponent, $\rho=4$; MS and BS antenna heights: $h_{m}=1.8 \mathrm{~m}$ and $h_{b}=10 \mathrm{~m}$ ). (a) Path loss exponent, $\alpha=2$. (b) Path loss exponent, $\alpha=2.5$. (c) Path loss exponent, $\alpha=2.8$. (d) Path loss exponent, $\alpha=3$. 
channel interfering cell only) to our propose interference model (first and second tier co-channel interfering cell) presented in this work (12).

Figure 6 shows the plot of $A S E$ versus cell radius $R$ for different path loss exponents $\alpha$ and carrier frequencies $f_{c}$. As expected the $A S E$ improves as the path loss exponent $\alpha$ increases, because the interfering signals are more attenuated. This is in agreement with existing work [11]. The graphs also quantified the fact that decreasing cell size increases the ASE. The curves in Fig. 6(a) show that for $f_{c}=0.9$ and $2 \mathrm{GHz}$, the second tier co-channel interfering cells have no effect on the $A S E$ as the curves for both the conventional and proposed model overlay. For carrier frequency $f_{c}=3.35 \mathrm{GHz}$ and cell

Table 5. Percentage decrease in area spectrum efficiency between the two interference model.

\begin{tabular}{|c|c|c|c|}
\hline \multicolumn{4}{|c|}{$h_{m}=1.8 \mathrm{~m}, h_{b}=10 \mathrm{~m}$ and $\rho=4$} \\
\hline Basic Path & Carrier & Cell Size & Percentage \\
\hline Loss Exponent $(\alpha)$ & Frequency & Radius (m) & Decrease $(\%)$ \\
\hline \multirow{5}{*}{2} & $900 \mathrm{MHz}$ & 100 & 3.96 \\
\hline & $2 \mathrm{GHz}$ & 100 & 6.80 \\
\hline & $3.35 \mathrm{GHz}$ & 100 & 9.68 \\
\hline & $8.45 \mathrm{GHz}$ & 100 & 15.85 \\
\hline & $15.75 \mathrm{GHz}$ & 100 & 19.47 \\
\hline \multirow{5}{*}{2.5} & $900 \mathrm{MHz}$ & 100 & 2.78 \\
\hline & $2 \mathrm{GHz}$ & 100 & 4.68 \\
\hline & $3.35 \mathrm{GHz}$ & 100 & 6.59 \\
\hline & $8.45 \mathrm{GHz}$ & 100 & 10.84 \\
\hline & $15.75 \mathrm{GHz}$ & 100 & 13.46 \\
\hline \multirow{5}{*}{2.8} & $900 \mathrm{MHz}$ & 100 & 2.29 \\
\hline & $2 \mathrm{GHz}$ & 100 & 3.8 \\
\hline & $3.35 \mathrm{GHz}$ & 100 & 5.25 \\
\hline & $8.45 \mathrm{GHz}$ & 100 & 8.62 \\
\hline & $15.75 \mathrm{GHz}$ & 100 & 10.68 \\
\hline \multirow{5}{*}{3} & $900 \mathrm{MHz}$ & 100 & 2.00 \\
\hline & $2 \mathrm{GHz}$ & 100 & 3.27 \\
\hline & $3.35 \mathrm{GHz}$ & 100 & 4.57 \\
\hline & $8.45 \mathrm{GHz}$ & 100 & 7.4 \\
\hline & $15.75 \mathrm{GHz}$ & 100 & 9.17 \\
\hline
\end{tabular}


size radius $R<200 \mathrm{~m}$ there was a decrease of $9.7 \%$ in $A S E$ between the conventional and proposed model, whiles for $R>200 \mathrm{~m}$ there was no decrease. When $f_{c}=8.45 \mathrm{GHz}$ for $R<500 \mathrm{~m}$ the decrease in $A S E$ was between $3.13-16.51 \%$, whiles for $R>500 \mathrm{~m}$ there was no much decrease in $A S E$ between the two models. For carrier frequency $f_{c}=15.75 \mathrm{GHz}$ and cell size radius $100 \mathrm{~m} \leq R \leq 1000 \mathrm{~m}$, there was a decrease in $A S E$ between 2.65-20\%. It can therefore be concluded that, for TDMAbased cellular systems operating at higher carrier frequencies as cell size reduces second tier co-channel interference becomes severe.

This behavior of decrease in $A S E$ as carrier frequency increases and cell radius decreases can be explained intuitively as follows; at higher carrier frequency the breakpoint distance from the transmitter

Table 6. Percentage decrease in area spectrum efficiency between the two interference model.

\begin{tabular}{|c|c|c|c|}
\hline \multicolumn{4}{|c|}{$h_{m}=1.8 \mathrm{~m}, h_{b}=10 \mathrm{~m}$ and $\rho=4$} \\
\hline Basic Path & Carrier & Cell Size & Percentage \\
\hline Loss Exponent $(\alpha)$ & Frequency & Radius (m) & Decrease $(\%)$ \\
\hline \multirow{5}{*}{2} & $900 \mathrm{MHz}$ & 500 & 0.8 \\
\hline & $2 \mathrm{GHz}$ & 500 & 1.12 \\
\hline & $3.35 \mathrm{GHz}$ & 500 & 1.52 \\
\hline & $8.45 \mathrm{GHz}$ & 500 & 3.14 \\
\hline & $15.75 \mathrm{GHz}$ & 500 & 5.28 \\
\hline \multirow{5}{*}{2.5} & $900 \mathrm{MHz}$ & 500 & 0.52 \\
\hline & $2 \mathrm{GHz}$ & 500 & 0.71 \\
\hline & $3.35 \mathrm{GHz}$ & 500 & 1.0 \\
\hline & $8.45 \mathrm{GHz}$ & 500 & 1.96 \\
\hline & $15.75 \mathrm{GHz}$ & 500 & 3.31 \\
\hline \multirow{5}{*}{2.8} & $900 \mathrm{MHz}$ & 500 & 0.44 \\
\hline & $2 \mathrm{GHz}$ & 500 & 0.6 \\
\hline & $3.35 \mathrm{GHz}$ & 500 & 0.78 \\
\hline & $8.45 \mathrm{GHz}$ & 500 & 1.5 \\
\hline & $15.75 \mathrm{GHz}$ & 500 & 2.45 \\
\hline \multirow{5}{*}{3} & $900 \mathrm{MHz}$ & 500 & 0.4 \\
\hline & $2 \mathrm{GHz}$ & 500 & 0.48 \\
\hline & $3.35 \mathrm{GHz}$ & 500 & 0.67 \\
\hline & $8.45 \mathrm{GHz}$ & 500 & 1.23 \\
\hline & $15.75 \mathrm{GHz}$ & 500 & 2.07 \\
\hline
\end{tabular}


becomes longer. Consequently, decreasing cell size will cause more cochannel interfering cells to be before the breakpoint where signals are attenuated according to the inverse square distance, thus decreasing the ASE. Figs. 6(b), 6(c) and 6(d), show that as $\alpha$ increases the decrease in $A S E$ between our model and conventional model reduces as expected. Because interfering signals before and after the breakpoint distance are more attenuated, even at higher carrier frequency. This confirms the statement by Zhou et al. in [18], that in conventional cellular system performance analysis, because large basic path loss exponent $\alpha$ are assumed second tier co-channel cell are neglected. However this may not be the case for emerging cellular wireless network as $\alpha$ becomes smaller.

Table 7. Percentage decrease in area spectrum efficiency between the two interference model.

\begin{tabular}{|c|c|c|c|}
\hline \multicolumn{4}{|c|}{$h_{m}=1.8 \mathrm{~m}, h_{b}=10 \mathrm{~m}$ and $\alpha=2$} \\
\hline Extra Path & Carrier & Cell Size & Percentage \\
Loss Exponent $(\rho)$ & Frequency & Radius $(\mathrm{m})$ & Decrease (\%) \\
\hline & $900 \mathrm{MHz}$ & 100 & 10.25 \\
& $2 \mathrm{GHz}$ & 100 & 13.51 \\
& $3.35 \mathrm{GHz}$ & 100 & 16.10 \\
& $8.45 \mathrm{GHz}$ & 100 & 20.48 \\
& $15.75 \mathrm{GHz}$ & 100 & 22.60 \\
\hline \multirow{5}{*}{3} & $900 \mathrm{MHz}$ & 100 & 6.36 \\
& $2 \mathrm{GHz}$ & 100 & 9.65 \\
& $3.35 \mathrm{GHz}$ & 100 & 12.49 \\
& $8.45 \mathrm{GHz}$ & 100 & 18.00 \\
& $15.75 \mathrm{GHz}$ & 100 & 21.03 \\
\hline & $900 \mathrm{MHz}$ & 100 & 2.56 \\
& $2 \mathrm{GHz}$ & 100 & 4.85 \\
& $3.35 \mathrm{GHz}$ & 100 & 7.49 \\
& $8.45 \mathrm{GHz}$ & 100 & 13.93 \\
& $15.75 \mathrm{GHz}$ & 100 & 18.15 \\
\hline & $900 \mathrm{MHz}$ & 100 & 0.79 \\
& $2 \mathrm{GHz}$ & 100 & 1.88 \\
& $3.35 \mathrm{GHz}$ & 100 & 3.50 \\
& $8.45 \mathrm{GHz}$ & 100 & 9.35 \\
& $15.75 \mathrm{GHz}$ & 100 & 14.35 \\
\hline
\end{tabular}


The results of the percentage decrease in $A S E$ between the two interference model; for different basic path loss exponents $\alpha$, carrier frequencies $f_{c}$ and cell size radii $R ; 100$ and $500 \mathrm{~m}$ are given in Tables 5 and 6 . Comparing the results for the conventional interference model presented in [11] to our propose interference model presented in this work (12), we can conclude that at higher carrier frequencies, smaller path loss exponent and smaller cell radius, second tier co-channel

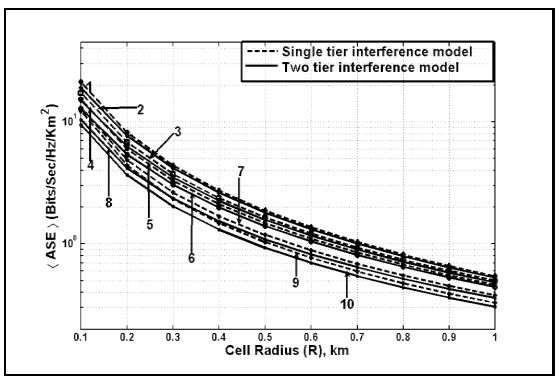

(a)

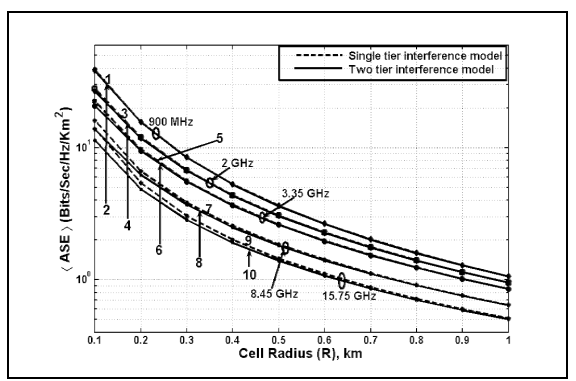

(c)

1 Single tier co-channel interfering model $\left(f_{c}=900 \mathrm{MHz}\right)$

2 Two tier co-channel interfering model $\left(f_{c}=900 \mathrm{MHz}\right)$

3 Single tier co-channel interfering model $\left(f_{c}=2 \mathrm{GHz}\right)$

4 Two tier co-channel interfering model $\left(f_{c}=2 \mathrm{GHz}\right)$

5 Single tier co-channel interfering model $\left(f_{c}=3.35 \mathrm{GHz}\right)$

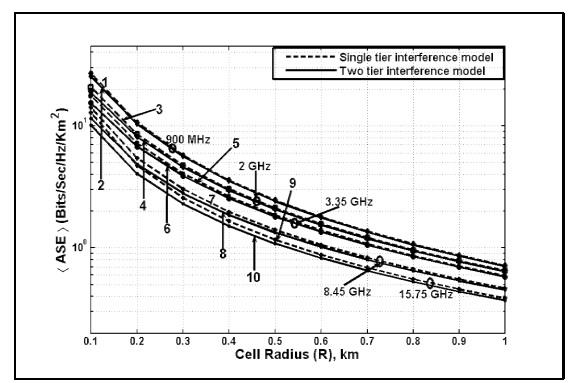

(b)

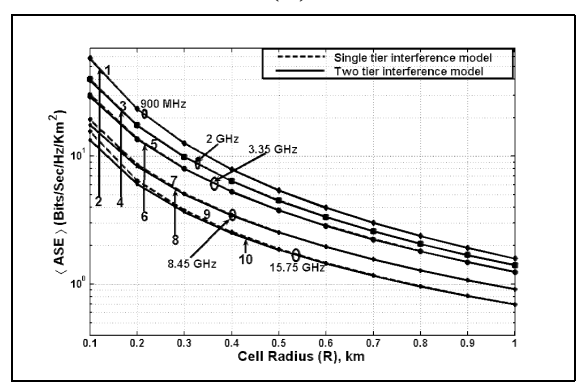

(d)

6 Two tier co-channel interfering model $\left(f_{c}=3.35 \mathrm{GHz}\right)$

7 Single tier co-channel interfering model $\left(f_{c}=8.45 \mathrm{GHz}\right)$

8 Two tier co-channel interfering model $\left(f_{c}=8.45 \mathrm{GHz}\right)$

9 Single tier co-channel interfering model $\left(f_{c}=15.75 \mathrm{GHz}\right)$

10 Two tier co-channel interfering model $\left(f_{c}=15.75 \mathrm{GHz}\right)$

Figure 7. Average uplink area spectral efficiency versus cell radius for different extra path loss exponents, $\rho$, and carrier frequencies, $f_{c}$. (Fully-loaded system with 6 and 12 co-channel interfering cells in the first and second tier; $N_{F I}=6$ and $\mathrm{N}_{S I}=12$; path loss exponent, $\alpha=2$; MS and BS antenna heights: $h_{m}=1.8 \mathrm{~m}$ and $h_{b}=10 \mathrm{~m}$ ). (a) Extra path loss exponent, $\rho=2$. (b) Extra path loss exponent, $\rho=3$. (c) Extra path loss exponent, $\rho=5$. (d) Extra path loss exponent, $\rho=8$. 
interference causes a decrease in the information capacity $(A S E)$ of a cellular wireless communication system.

Figure 7 indicates the effect of extra path loss exponent $\rho$ on the performance of cellular wireless system operating at higher carrier frequencies and smaller cell size radius. The curves show that as $f_{c}$ increases from 0.9 to $15.75 \mathrm{GHz}$, and cell radius decreases from 1000 $100 \mathrm{~m}$, the $A S E$ increases exponential. The figure confirms that $A S E$ is an increasing function of both $\rho$ and $R$. Fig. 7(a), shows that for the case when $\rho=2$ and $f_{c}=0.9,2$ and $3.35 \mathrm{GHz}$. The curves show a small decrease in $A S E$ from $R \leq 300 \mathrm{~m}$. However, for $f_{c}=8.45$, and $15.75 \mathrm{GHz}$, when $R \leq 500 \mathrm{~m}$ the decrease in $A S E$ between our model and existing model are bigger.

An interesting observation is that for $R=300 \mathrm{~m}$ the $A S E$ at $8.45 \mathrm{GHz}$ for the two tier model equals the $15.75 \mathrm{GHz}$ single tier model. This confirms the importance of the consideration of second tier co-channel interference in cellular system information capacity performance analysis at higher carrier frequencies and smaller cell size radius. Fig. 7(b), shows that for the case when $\rho=3$ and $f_{c}=0.9$, 2 and $3.35 \mathrm{GHz}$. The curves for the ASE for the two models overlay each other. However, for $f_{c}=8.45$, and $15.75 \mathrm{GHz}$, when $R \leq 500 \mathrm{~m}$ the decrease in $A S E$ between our proposed model and conventional model are between 5-18\%, and 21.74-7.36\%. Figs. 7(c) and 7(d), reveal

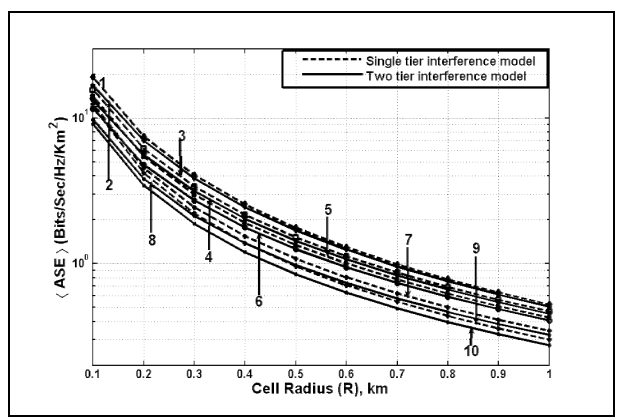

1 Single tier co-channel interfering model $\left(f_{c}=900 \mathrm{MHz}\right)$

6 Two tier co-channel interfering model $\left(f_{c}=3.35 \mathrm{GHz}\right)$

2 Two tier co-channel interfering model $\left(f_{c}=900 \mathrm{MHz}\right)$

7 Single tier co-channel interfering model $\left(f_{c}=8.45 \mathrm{GHz}\right)$

3 Single tier co-channel interfering model $\left(f_{c}=2 \mathrm{GHz}\right)$

8 Two tier co-channel interfering model $\left(f_{c}=8.45 \mathrm{GHz}\right)$

4 Two tier co-channel interfering model $\left(f_{c}=2 \mathrm{GHz}\right)$

9 Single tier co-channel interfering model $\left(f_{c}=15.75 \mathrm{GHz}\right)$

5 Single tier co-channel interfering model $\left(f_{c}=3.35 \mathrm{GHz}\right)$

10 Two tier co-channel interfering model $\left(f_{c}=15.75 \mathrm{GHz}\right)$

Figure 8. Average uplink area spectral efficiency versus cell radius for different $f_{c}$. (Fully-loaded system with 6 and 12 co-channel interfering cells in the first and second tier; $N_{F I}=6$ and $N_{S I}=12$; path loss exponent, $\alpha=2$ and extra path loss exponent $\rho=2$; BS and MS antenna height, $h_{b}=15 \mathrm{~m}$ and $\left.h_{m}=1.8 \mathrm{~m}\right)$. 
that as $\rho$ increases the second tier co-channel interference become less severe. This contributes to decrease in $A S E$ between the two models being minimal. Tables 7 and 8 show the results of percentage decrease in $A S E$ between the two interference model; for different extra path loss exponents $\rho$, carrier frequencies $f_{c}$ and cell size radii $R ; 100$ and $500 \mathrm{~m}$.

Comparing Figs. 7(a) and 8, reveals the effect of BS antenna height $h_{b}$ on the system information capacity performance at different carrier frequencies. It can be observed that for $h_{b}=15 \mathrm{~m}$ and $\rho=2$ for $f_{c}=0.9,2$ and $3.35 \mathrm{GHz}$ the curves show more decrease in $A S E$ from $R \leq 300 \mathrm{~m}$ as compared to Fig. 7(a). This is because as $h_{b}$ increases

Table 8. Percentage decrease in area spectrum efficiency between the two interference model.

\begin{tabular}{|c|c|c|c|}
\hline \multicolumn{4}{|c|}{$h_{m}=1.8 \mathrm{~m}, h_{b}=10 \mathrm{~m}$ and $\alpha=2$} \\
\hline Extra Path & Carrier & Cell Size & Percentage \\
\hline Loss Exponent $(\rho)$ & Frequency & Radius (m) & Decrease $(\%)$ \\
\hline \multirow{5}{*}{2} & $900 \mathrm{MHz}$ & 500 & 3.64 \\
\hline & $2 \mathrm{GHz}$ & 500 & 4.44 \\
\hline & $3.35 \mathrm{GHz}$ & 500 & 5.29 \\
\hline & $8.45 \mathrm{GHz}$ & 500 & 7.78 \\
\hline & $15.75 \mathrm{GHz}$ & 500 & 10.24 \\
\hline \multirow{5}{*}{3} & $900 \mathrm{MHz}$ & 500 & 1.67 \\
\hline & $2 \mathrm{GHz}$ & 500 & 2.18 \\
\hline & $3.35 \mathrm{GHz}$ & 500 & 2.80 \\
\hline & $8.45 \mathrm{GHz}$ & 500 & 5.0 \\
\hline & $15.75 \mathrm{GHz}$ & 500 & 7.36 \\
\hline \multirow{5}{*}{5} & $900 \mathrm{MHz}$ & 500 & 0.39 \\
\hline & $2 \mathrm{GHz}$ & 500 & 0.59 \\
\hline & $3.35 \mathrm{GHz}$ & 500 & 0.84 \\
\hline & $8.45 \mathrm{GHz}$ & 500 & 2.00 \\
\hline & $15.75 \mathrm{GHz}$ & 500 & 3.9 \\
\hline \multirow{5}{*}{8} & $900 \mathrm{MHz}$ & 500 & - \\
\hline & $2 \mathrm{GHz}$ & 500 & - \\
\hline & $3.35 \mathrm{GHz}$ & 500 & 0.16 \\
\hline & $8.45 \mathrm{GHz}$ & 500 & 0.55 \\
\hline & $15.75 \mathrm{GHz}$ & 500 & 1.49 \\
\hline
\end{tabular}


$g$ increases causing the second tier interfering cell to be in the region before $g$. For $f_{c}=8.45$, and $15.75 \mathrm{GHz}$, when $R \leq 500 \mathrm{~m}$ the decrease in $A S E$ between our model and the existing are much bigger than in Fig. 7 (a). Unlike the case when $h_{b}=10$, where at $R=300 \mathrm{~m}$ the $A S E$ at $8.45 \mathrm{GHz}$ for the two tier model equals that of the $15.75 \mathrm{GHz}$ single tier model. For the case of $h_{b}=15$, it is not equal.

Figure 9 illustrates the effect of the effective road height on $A S E$

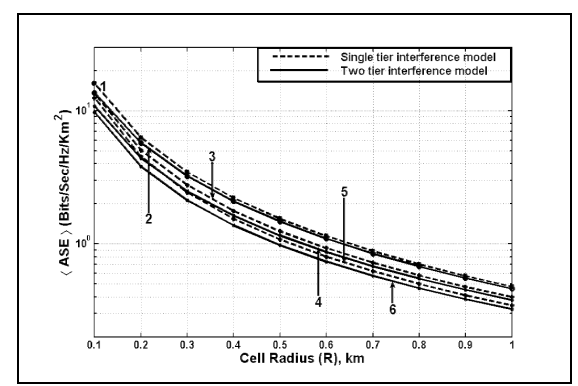

(a)

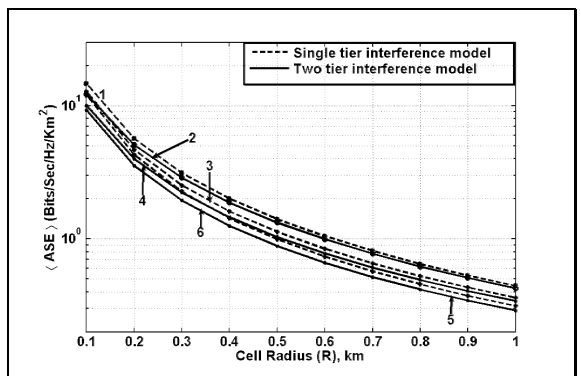

(c)

1 Single tier co-channel interfering model $\left(f_{c}=3.35 \mathrm{GHz}\right)$

2 Two tier co-channel interfering model $\left(f_{c}=3.35 \mathrm{GHz}\right)$

3 Single tier co-channel interfering model $\left(f_{c}=8.45 \mathrm{GHz}\right)$

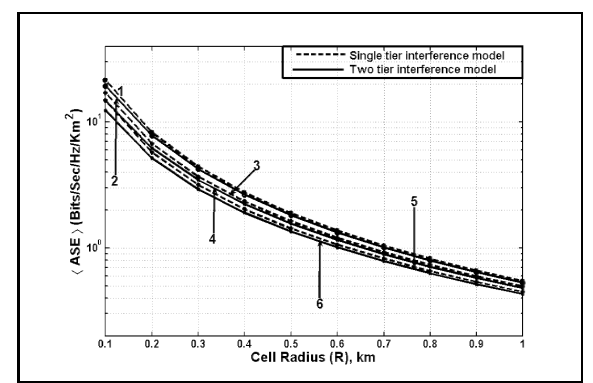

(b)

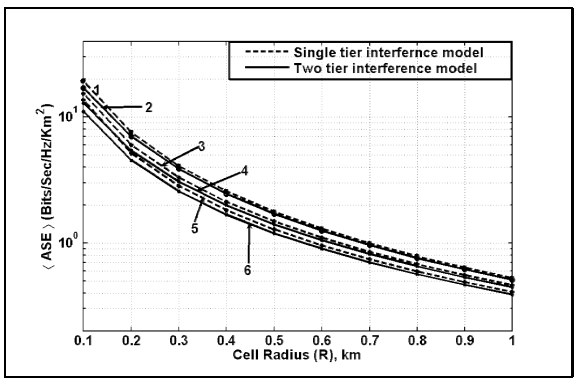

(d)

4 Two tier co-channel interfering model $\left(f_{c}=8.45 \mathrm{GHz}\right)$

5 Single tier co-channel interfering model $\left(f_{c}=15.75 \mathrm{GHz}\right)$

6 Two tier co-channel interfering model $\left(f_{c}=15.75 \mathrm{GHz}\right)$

Figure 9. Average uplink area spectral efficiency versus cell radius for light and heavy vehicular traffic with effective road heights, $h=0.3$ and $1.29 \mathrm{~m}$ and different carrier frequencies, $f_{c}$. (Fully-loaded system with 6 and 12 co-channel interfering cells in the first and second tier; $N_{F I}=6$ and $N_{S I}=12$; path loss exponent, $\alpha=2$ and extra path loss exponent $\rho=2$; MS antenna height, $h_{m}=1.8 \mathrm{~m}$ ). (a) Light vehicular traffic, BS antenna height, $h_{b}=10 \mathrm{~m}$. (b) Heavy vehicular traffic, BS antenna height, $h_{b}=10 \mathrm{~m}$. (c) Light vehicular traffic, BS antenna height, $h_{b}=15 \mathrm{~m}$. (d) Heavy vehicular traffic, BS antenna height, $h_{b}=15 \mathrm{~m}$. 
at carrier frequency greater than $2 \mathrm{GHz}$, when the first and second tier co-channel interfering cells are active. We found that previous result in this paper still holds. This figure shows that the decrease in $A S E$ increases as carrier frequency increases and cell size radius decreases. It is observed that the decrease in $A S E$ is lesser for heavy vehicular traffic as compare to light vehicular traffic. For the case of light vehicular traffic at $R=100 \mathrm{~m}$, for $f_{c}=3.35,8.45$ and $15.75 \mathrm{GHz}$ the decrease in $A S E$ is $15.11,19.55$ and $21.94 \%$, whilst for heavy vehicular traffic it is 9.94, 13.69 and $16.61 \%$. Then, we conclude that at microwave carrier frequencies greater than $2 \mathrm{GHz}$ and smaller cell size radius, the effect of second tier co-channel interference is minimal during heavy vehicular traffic (day time) relative to light vehicular traffic (night time). This is because the breakpoint distance at day time is bigger than that at night time. This is due to the increment of the effective road height [refer to 3]. The figures show that increasing $h_{b}$ leads to second tier co-channel interference becoming more severe. The figure also reveals that even if $h_{b}$ is increased, the decrease in $A S E$ is still lesser for day time.

The effect of shadowing on the $A S E$ at higher carrier frequency is

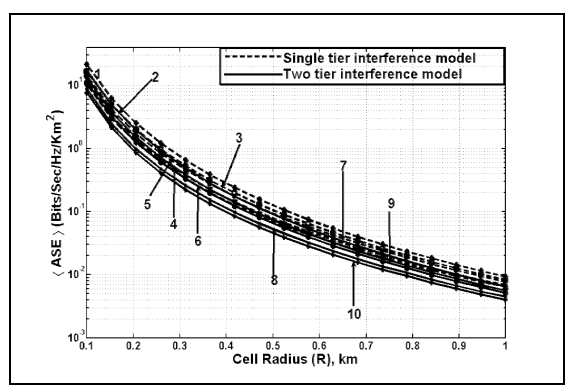

(a)

1 Single tier co-channel interfering model $\left(f_{c}=900 \mathrm{MHz}\right)$ 2 Two tier co-channel interfering model $\left(f_{c}=900 \mathrm{MHz}\right)$ 3 Single tier co-channel interfering model $\left(f_{c}=2 \mathrm{GHz}\right)$ 4 Two tier co-channel interfering model $\left(f_{c}=2 \mathrm{GHz}\right)$ 5 Single tier co-channel interfering model $\left(f_{c}=3.35 \mathrm{GHz}\right)$

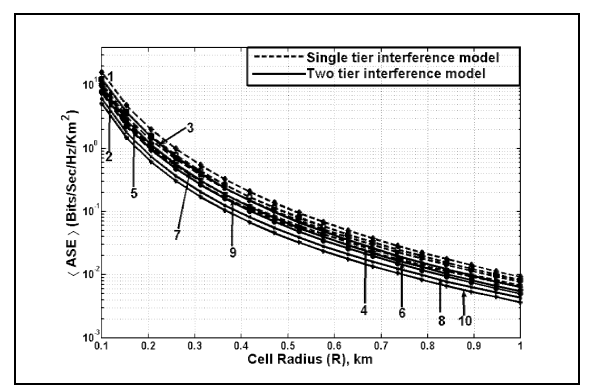

(b)

6 Two tier co-channel interfering model $\left(f_{c}=3.35 \mathrm{GHz}\right)$

7 Single tier co-channel interfering model $\left(f_{c}=8.45 \mathrm{GHz}\right)$

8 Two tier co-channel interfering model $\left(f_{c}=8.45 \mathrm{GHz}\right)$

9 Single tier co-channel interfering model $\left(f_{c}=15.75 \mathrm{GHz}\right)$ 10 Two tier co-channel interfering model $\left(f_{c}=15.75 \mathrm{GHz}\right)$

Figure 10. Average uplink area spectral efficiency versus cell radius in a shadow environment with different carrier frequencies, $f_{c}$. (Fullyloaded system with 6 and 12 co-channel interfering cells in the first and second tier; $N_{F I}=6$ and $N_{S I}=12$; path loss exponent, $\alpha=2$ and extra path loss exponent $\rho=2$; MS antenna height, $h_{m}=1.8 \mathrm{~m}$ ). (a) Shadowing standard deviation, $\sigma=8 \mathrm{~dB}$. (b) Shadowing standard deviation, $\sigma=12 \mathrm{~dB}$. 
shown in Fig. 10. The curves have the same relative shape as previous curves in this paper. However, the decrease in $A S E$ between the two models is always bigger. This is because of the variability of the signal. The figure shows that the decrease in information capacity between the two model becomes bigger as the carrier frequency increases and cell size radius decreases. Comparing Figs. 10(a) and 10(b) reveals that as $\sigma$ increases the second tier co-channel interference become severe. Fig. 11, shows that even in a shadow environment the decrease in $A S E$ is still lesser for heavy vehicular traffic compare to light vehicular traffic.

We see that in all cases the $A S E$ curves for different interference configurations have the same relative shape. Then from Figs. 9 and 11, it is concluded that, for a TDMA-based cellular system operating at higher carrier frequencies, for heavy vehicular traffic the decrease in $A S E$ due to second tier co-channel interference is minimal relative to the one obtained for light vehicular traffic. This is in agreement with results reported in [6]. However, in [6] the evaluation was based on the outage probability, a value for radius and a cigar-shaped microcellular

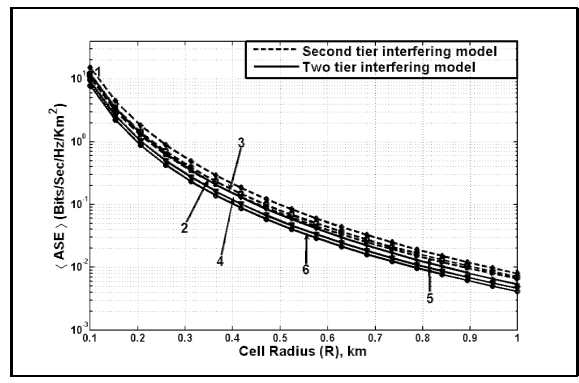

(a)

1 Single tier co-channel interfering model $\left(f_{c}=3.35 \mathrm{GHz}\right)$

2 Two tier co-channel interfering model $\left(f_{c}=3.35 \mathrm{GHz}\right)$

3 Single tier co-channel interfering model $\left(f_{c}=8.45 \mathrm{GHz}\right)$

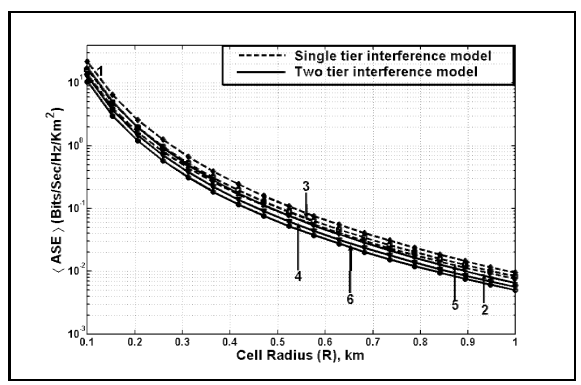

(b)

4 Two tier co-channel interfering model $\left(f_{c}=8.45 \mathrm{GHz}\right)$

5 Single tier co-channel interfering model $\left(f_{c}=15.75 \mathrm{GHz}\right)$

6 Two tier co-channel interfering model $\left(f_{c}=15.75 \mathrm{GHz}\right)$

Figure 11. Average uplink area spectral efficiency versus cell radius for light and heavy vehicular traffic with effective road heights, $h=0.3$ and $1.29 \mathrm{~m}$ and different carrier frequencies, $f_{c}$ in a shadowed environment. (Fully-loaded system with 6 and 12 co-channel interfering cells in the first and second tier; $N_{F I}=6$ and $N_{S I}=12$; path loss exponent, $\alpha=2$ and extra path loss exponent $\rho=2$; BS and MS antenna height, $h_{b}=10 \mathrm{~m}$, and $h_{m}=1.8 \mathrm{~m}$ and shadowing standard deviation, $\sigma=8 \mathrm{~dB}$ ). (a) Effective road height $h=0.3 \mathrm{~m}$. (b) Effective road height $h=1.29 \mathrm{~m}$. 
scenario. The author found that the outage probability is improved for heavy vehicular traffic as compared to light vehicular traffic. In addition, we have found that second tier co-channel interfering cells become severe as cell size radius reduces and carrier frequency increases.

\section{CONCLUSION}

We studied and analyzed the impact of both system and propagation loss parameters on the information capacity performance of a TDMA based cellular wireless communication system operating at higher carrier frequency and smaller cell size radius, when both first and second tier co-channel interference are active. Our studies and analysis were based on the two slope propagation model characterized by lognormal shadowing and path loss.

From the results, we can conclude that for higher carrier frequencies and smaller cell size radius, second tier co-channel interference becomes active. As a result, the information capacity of the cellular wireless communication system is reduced. We also conclude that as the basic path loss exponent $\alpha$ decreases the second tier co-channel interference becomes severe. Likewise when the carrier frequency increases and cell size radius reduces. In the case where shadowing is considered, we can conclude that the higher the shadowing coefficient the more severe is the second tier co-channel interference. In future work, it may be interesting to study the effects of sectorization, correlation coefficient and multipath fading. Though it may be expensive to carry out an experiment to compare simulated results to experimental result, in future we may perform an experiment for results comparison.

\section{REFERENCES}

1. Lee, W. C. Y., "Spectrum efficiency in cellular," IEEE Trans. Veh. Technol., Vol. 38, 69-75, May 1989.

2. Pahlavan, K. and A. H. Levesque, "Wireless data communication," Proc. IEEE, Vol. 82, 1398-1430, Sep. 1994.

3. Takada, J., J. Fu, H. Zhu, and T. Kobayashi, "Spatiotemporal channel characterization in a suburban non line-of-sight microcellular environment," IEEE J. Select. Areas Commun., Vol. 20, No. 3, 532-538, Apr. 2002.

4. Masui, H., T. Kobayashi, and M. Akaike, "Microwave path-loss 
modeling in urban line-of-sight environments," IEEE J. Select. Areas Commun., Vol. 20, No. 6, 1151-1155, Aug. 2002.

5. Kitao, K. and S. Ichitsubo, "Path loss prediction formula for microcell in $400 \mathrm{MHz}$ to $8 \mathrm{GHz}$ band," IET Electronics Letters, Vol. 40, No. 11, 685-687, May 2004.

6. Hernández-Valdez, G., F. A. Cruz-Pérez, and D. Lara-Rodríguez, "Sensitivity of the system performance to the propagation parameters in LOS microcellular environments," IEEE Trans. Veh. Technol., Vol. 57, No. 6, 3488-3508, Nov. 2008.

7. Cox, D. C., R. R. Murray, and A. W. Norris, "Antenna height dependence of $800 \mathrm{MHz}$ attenuation measured in houses," IEEE Trans. Veh. Technol., Vol. 34, No. 2, 108-115, May 1985.

8. Green, E., "Radio link design for microcellular systems," British Telecom. Technology, Vol. 8, No. 1, 1990.

9. Cruz-Perez, F. A. and D. Lara-Rodriguez, "Impact of the breakpoint distance on the reverse link capacity of a CDMA manhattan like microcellular system," Proc. 5th IEEE International Symposium on Spread Spectrum Techniques and Applications (ISSSTA'1998), Vol. 1, 262-266, Sun City, South Africa, Sep. 1998.

10. Min, S. and H. L. Bertoni, "Effect of path loss on CDMA system design for highway microcells," Proc. 48th IEEE Vehicular Technology Conference (VTC'1998), 1009-1013, Ottawa, Canada, May 1998.

11. Alouini, M. and A. J. Goldsmith, "Area spectral efficiency of cellular mobile radio systems," IEEE Trans. Veh. Technol., Vol. 48, No. 4, 1047-1065, Jul. 1999.

12. Ho, C., J. Copeland, C. Lea, and G. Stüber, "Impact of the cell size on the cell's Erlang capacity and call admission control in the DS/CDMA cellular networks," Proc. 51st IEEE Vehicular Technology Conference (VTC'2000-Spring), Vol. 1, 385389, May 2000.

13. Hernandez-Valdez, G., F. A. Cruz-Perez, and M. Lara, "Impact of the cell size and the propagation model parameters on the performance of microcellular networks," Proc. 11th IEEE International Symposium on Personal, Indoor and Mobile Radio Communications (PIMRC'2000), Vol. 1, 292-296, London, UK, 2000.

14. Har, D. and H. L. Bertoni, "Effect of anisotropic propagation modeling on microcellular system design," IEEE Trans. Veh. Technol., Vol. 49, No. 4, 1303-1313, Aug. 2000. 
15. Ahmed, B. T., M. C. Ramon, and L. de Haro Ariet, "Capacity and interference statistics of highways W-CDMA cigar-shaped microcells (uplink analysis)," IEEE Commun. Lett., Vol. 6, No. 5, 172-174, Aug. 2002.

16. Anang, K. A., P. B. Rapajic, T. I. Eneh, and G. Oletu, "Sensitivity of information capacity of land mobile cellular system to the base station antenna height at higher microwave frequencies," Proc. 3rd International Conference on Computer Research and Development (ICCRD'2011), Vol. 3, 167-172, Shanghai, China, May 2011.

17. Anang, K. A., P. B. Rapajic, T. I. Eneh, and B. Lawal, "Sensitivity of information capacity of land mobile cellular system to propagation loss parameters at higher microwave frequencies," Proc. "7th IEEE International Wireless Communications and Mobile Computing Conference, 630-635, Istanbul, Turkey, Jul. 2011.

18. Zhou, S., M. Zhao, X. Xu, J. Wang, and Y. Yao, "Distributed wireless communication system: A new architecture for future public wireless access," IEEE Commun. Mag., Vol. 41, 108-113, 2003.

19. Anang, K. A., P. B. Rapajic, T. I. Eneh, and Y. Nijsure, "Minimum cell size for information capacity increase in cellular wireless network," Proc. 73rd IEEE Vehicular Technology Conference (VTC'2011), 305-311, Budapest, Hungary, May 2011.

20. Ge, X., K. Huang, C. X. Wang, X. Hong, and X. Yang, "Capacity analysis of a multi-cell multi-antenna cooperative cellular network with co-channel interference," IEEE Trans. Wireless Commun., Vol. 10, No. 10, 3298-3309, Oct. 2011.

21. Nisirat, M. A., M. Ismail, L. Nissirat, and S. A. Alkhawaldeh, "A terrain roughness correction factor for Hata path loss model at $900 \mathrm{MHz}, "$ Progress In Electromagnetics Research C, Vol. 22, 11-22, 2011.

22. Phaebua, K., C. Phongcharoenpanich, M. Krairiksh, and T. Lertwiriyaprapa, "Path-loss prediction of radio wave propagation in an orchard by using modified UTD method," Progress In Electromagnetics Research, Vol. 128, 347-363, 2012.

23. Sirkova, I., "Propagation factor and path loss simulation results for two rough surface reflection coefficients applied to the microwave ducting propagation over the sea," Progress In Electromagnetics Research M, Vol. 17, 151-166, 2011.

24. Caluyo, F. S. and J. C. D. Cruz, "Antenna characterization and determination of path loss exponents for $677 \mathrm{MHz}$ channel using fixed and portable digital terrestrial television," Progress In 
Electromagnetics Research C, Vol. 29, 149-161, 2012.

25. Nešković, A., N. Nešković, and D. Paunocć, "Macrocell electric field strength prediciton model based upon artificial neural networks," IEEE J. Select. Areas Commun., Vol. 20, No. 6, 11701176, Aug. 2002.

26. Cruz-Perez, F. A., D. Lara-Rodriguez, and M. Lara, "Full- and half-square cell plans in urban CDMA microcellular networks," IEEE Trans. Veh. Technol., Vol. 52, No. 3, 502-511, May 2003.

27. Oda, Y., K. Tsuunekawa, and M. Hata, "Advanced los pathloss model in microcellular mobile communications," IEEE Trans. Veh. Technol., Vol. 49, No. 6, 2121-2125, Nov. 2000.

28. Zhao, X., J. Kivinen, P. Vainikainen, and K. Skog, "Propagation characteristics for wideband outdoor mobile communications at $5.3 \mathrm{GHz}, "$ IEEE J. Select. Areas Commun., Vol. 20, No. 3, 507$514,2002$.

29. Sarkar, T. K., Z. Ji, K. Kim, A. Medouri, and M. SalazarPalma, "A survey of various propagation models for mobile communication," IEEE Antennas Propagat. Mag., Vol. 45, 51-74, Jun. 2003.

30. Green, E. and M. Hata, "Microcellular propagation measurements in an urban environment," Proc. 1st IEEE International Symposium on Personal, Indoor and Mobile Radio Communications (PIMRC'1991), 324-328, London, UK, Sep. 1991.

31. G. TR25.996, "3GPP SCM channel models," 3GPP TR25.996, Vol. v6.1.0, Sep. 2003.

32. ITU, "Propagation data and prediction methods for planning of short-range outdoor radiocommunication systems and radio local area networks in the frequency range $300 \mathrm{MHz}$ to $100 \mathrm{GHz}$," Recommendation ITU-R P.1411-1, iTU Radiocommunication Assembly, 2012.

33. Stüber, G. L., Principles of Mobile Communication, 2nd Edition, 98-100, Kluwer Academic, Norwell, MA, 2001.

34. Lee, W. C. Y., Mobile Communication Design Fundamentals, 142, John Wiley \& Sons, New York, NY, 1993.

35. Singh, S., N. B. Mehta, A. F. Molisch, and A. Mukhopadhyay, "Moment-matched lognormal modeling of uplink interference with power control and cell selection," IEEE Trans. Wireless Commun., Vol. 9, No. 3, 932-938, Mar. 2010. 